\title{
ELUCUBRAÇÕES SOBRE UM SONHO ELUCIDATIVO: $O$ ERRO FETICHISTA E $O$ ACERTO FREUDIANO
}

Simone Perelson

Professora adjunta do Programa de Pós-graduação em Teoria Psicanalítica e da Escola de Comunicação/ UFRJ.
RESUMO: A partir da interpretação freudiana de um sonho, da definição freudiana de fetichismo e de alguns comentários de Slavoj Zizek e Wladimir Safatle sobre os mesmos, teceremos algumas considerações sobre: 1 . O valor que a interpretação freudiana concede aos conteúdos latentes e à forma manifesta dos sonhos. 2. O estatuto faltoso do objeto do desejo. 3. A relação que a realização do desejo supõe entre desencontro e encontro e entre engano e verdade. 4. O problema do fetichismo.

Palavras-chave: Freud, Zizek, Safatle, sonho, fetichismo.

ABSTRACT: Meditation on an instructive dream: the fetishistic error and the Freudian hit. From the Freudian interpretation of a dream, from the Freudian definition of fetishism and from some reviews of Slavoj Zizek and Wladimir Safatle about the same, we will make some considerations about: 1 . The value that the Freudian interpretation accords to latent contents and to the actual shape of dreams. 2. The defaulting status of the object of desire. 3. The relationship that the accomplishment of desire implies between encounter and confrontation and between deception and truth. 4. The problem of fetishism.

Keywords: Freud, Zizek, Safatle, dream, fetichism. 
$\mathrm{E}$ ntre os inúmeros sonhos narrados por Freud, há um que, a seu ver, merece ser registrado com pormenores. Trata-se de um sonho muito nítido tido por um jovem e que o fez recordar-se de algumas fantasias de sua meninice.

"Sonhou que era noite e se encontrava num hotel, numa estação de veraneio. Confundiu o número de seu quarto e entrou num errado, no qual uma senhora idosa e suas duas filhas estavam se despindo para dormir. Prosseguiu ele: 'Aqui, existem algumas lacunas no sonho; está faltando algo.”' (FREUD, 1900/1974, p.353)

Por mais que se esforce, o jovem não consegue preencher as lacunas de sua lembrança, ou ainda, nos termos de Freud, "recordar-se da essência e curso da fantasia infantil à qual o sonho evidentemente fazia alusão" (idem, p.354). Por fim, entretanto, conclui ele,

"surgiu a verdade de que aquilo que procurava já se encontrava em seu poder, em sua observação sobre a parte obscura do sonho. As lacunas eram os orifícios genitais das mulheres que iam deitar-se e 'alguma coisa que estava faltando' descrevia o aspecto principal dos órgão genitais femininos." (ibidem)

A fantasia à qual o sonho fazia alusão não poderia ser senão aquela segundo a qual ali onde o menino via uma lacuna no corpo feminino, algo se escondia à sua visão, a saber, o falo.

O relato deste sonho e a interpretação que lhe dá Freud condensam, articulam e elucidam de modo notável um número surpreendente de ideias e teorias freudianas.

Vejamos: se a fantasia do jovem sonhador é que algum conteúdo se encobria por trás de seu esquecimento, a fantasia do menino que ele fora é que por trás da falta percebida no corpo feminino se esconderia o falo. O que é admirável e muito perspicaz na interpretação sugerida para o sonho é:

a) A articulação empreendida, ou ainda o deslizamento operado por Freud entre a fantasia do jovem diante do esquecimento de uma parte do sonho e a fantasia do menino diante da percepção da castração feminina, nos dando a perceber que ambas obedecem a uma mesma estrutura lógica: "por trás da falta, algo se esconde".

b) A virada que sua interpretação realiza: nada há por trás da lacuna senão a própria lacuna; nada há por trás da falta senão a própria falta. Eis a mensagem do sonho. Eis também uma indicação de como devemos ler a afirmação freudiana segundo a qual é nas lacunas do discurso da consciência que devemos procurar o inconsciente: este não se revela "por trás”, mas na própria lacuna. Eis ainda uma indicação de como devemos conceber o estatuto faltoso do objeto do desejo: a 
falta não deve ser confundida com aquilo que surge no lugar do objeto do desejo originário perdido, mas sim como esse próprio objeto.

c) Da mesma forma que não há conteúdo oculto algum por trás da forma lacunar da lembrança do sonho, a própria mensagem do sonho, se quisermos usar essa expressão, tampouco se revela como algo a ser decifrado "por trás" das palavras emitidas pelo sonhador ao narrar seu sonho, mas sim como algo que está escancarado na própria forma lacunar de seu relato. Para que a mensagem do sonho possa ser alcançada, basta escutar as palavras de seu narrador.

Como Freud observa, vale citá-lo mais uma vez: "aquilo que procurava já se encontrava em seu poder em sua observação sobre a parte obscura [isto é, sobre a lacuna] do sonho". Eis uma formulação que não pode deixar de nos levar a pensar na homologia da solução que Freud dá aqui para o enigma do sonho - e, podemos acrescentar, para os enigmas do inconsciente e do objeto do desejo — com a solução hegeliana tal como a descreve Zizek (1991). Como sublinha o autor, "o que a princípio se apresentava como um obstáculo tornase, no giro dialético, o próprio indicador de que tocamos na verdade. Somos imersos na coisa pelo que apenas parecia velá-la, o que implica que 'a própria coisa' é furada" (p.114). Em outros termos, a solução hegeliana não é a de que o sujeito não pode obter o que busca, mas a de que já tem o que busca, "sob a própria forma da perda” (p.126).

A esses três aspectos acima salientados, acrescentamos ainda um último, no qual iremos mais longamente nos deter: se o que explica a posição do fetichista é a fixação libidinal do homem num conteúdo que de alguma forma pode permitirlhe rejeitar a castração da mulher, a interpretação que permite ao analista não cair na armadilha fetichista implica, por sua vez, não fazer o jogo de buscar revelar o conteúdo oculto por trás da forma manifesta do relato do sonho.

Talvez não haja uma interpretação freudiana de sonho mais adequada do que esta para ilustrar a homologia fundamental que, ao ver de Zizek, podemos encontrar no processo interpretativo de Marx e Freud, na abordagem que ambos fazem do segredo da mercadoria ou do sonho. "Nos dois casos" deve-se evitar a cegueira, o fascínio propriamente fetichista do conteúdo oculto por trás da forma: o segredo a ser desvendado pela análise não é o conteúdo dissimulado pela forma (forma do sonho, forma da mercadoria), mas, muito pelo contrário, é essa própria forma" (ZIZEK, 1991, p.131).

Portanto, como observa Zizek, não é possível confundirmos o sonho com seu conteúdo latente. De fato, o próprio Freud foi suficientemente explícito e bastante enfático ao sublinhar que, se por um lado, não se deve buscar o significado de um sonho em seu conteúdo manifesto, tampouco devemos buscar sua essência em seu conteúdo latente. Esta advertência pode ser encontrada ao menos em dois momentos de sua obra: em primeiro lugar, em suas conferências 
sobre os sonhos pronunciadas entre 1915 e 1916 (FREUD, 1916-17 [1915-16] /1974) e, em segundo lugar, numa nota de rodapé acrescentada em 1925 ao livro A interpretação de sonhos (FREUD, 1900/1974).

\section{O SONHO E O LUGAR DO INCONSCIENTE: FORMA E SUPERFÍCIE}

Na conferência dedicada ao tema da elaboração onírica, Freud sublinha o risco do deslocamento de interesse teórico da elaboração onírica para os pensamentos oníricos latentes e adverte que "não existe justificativa para (...) substituir o sonho, completamente, pelos pensamentos oníricos latentes” (FREUD, 1916-17 [1915-16] /1974, p.218). Como, em seguida, ele observa:

"É estranho que os achados da psicanálise possam prestar-se a um mau uso que possibilite confusões. Não se pode dar o nome de 'sonho' a nenhuma outra coisa que não seja produto da elaboração onírica — isto é, a forma em que os pensamentos latentes foram transmutados pela elaboração onírica." (ibidem)

Na conferência sobre os sonhos como realização de desejos, Freud volta a advertir seus ouvintes para que estes não venham a cometer um "equívoco tolo que pode nos roubar o fruto de nossos esforços com os sonhos" (idem, p.265) e a insistir no fato de que "a única coisa essencial a respeito dos sonhos é a elaboração onírica que modificou o material ideativo” (idem, p.267). É nessa medida que, sustenta ele,

“quando falam de 'sonho', devem querer significar ou o sonho manifesto - isto é o produto da elaboração onírica — ou, no máximo, também a própria elaboração onírica - isto é, o processo psíquico que forma o sonho manifesto a partir dos pensamentos oníricos latentes. Qualquer outro uso da palavra significa confusão de ideias, e só pode levar a maus resultados.” (idem, p.266)

A nota de rodapé que Freud acrescenta em 1925 ao livro A interpretação de sonhos revela que sua preocupação quanto aos riscos dessa confusão de ideias se manteve tão inalterada quanto justificada. Eis os termos com os quais ele se expressa na nota:

“Época ouve em que eu achava extraordinariamente difícil acostumar os leitores à distinção entre o conteúdo manifesto dos sonhos e os pensamentos oníricos latentes. (...) Mas agora que os analistas pelo menos concordaram em substituir o sonho manifesto pelo significado revelado por sua interpretação, muitos deles se tornaram culpados em incidir em outra confusão à qual se apegam com igual obs- 
tinação. Procuram encontrar a essência dos sonhos em seu conteúdo latente e, ao agirem dessa forma, desprezam a distinção entre os pensamentos oníricos latentes e o trabalho onírico. No fundo, os sonhos nada mais são que uma forma particular de pensamento (...). É a elaboração do sonho que cria essa forma, sendo ela sozinha a essência do sonhar." (FREUD, 1900/1974, p.541)

Portanto, conclusão que pode surpreender a muitos: a essência dos sonhos não se confunde com os pensamentos latentes que deram origem a eles, que tiveram sua forma de expressão modificada pela elaboração onírica e aos quais se acessa, através da associação livre, pela interpretação. A essência do sonho não se confunde com o conteúdo ou com o significado ocultos revelados por sua interpretação. Aliás, como observa Zizek, “'se buscarmos o ‘segredo do sonho’ em seu conteúdo latente ocultado pelo texto manifesto, ficaremos desapontados: só esbarraremos num pensamento essencialmente 'normal', cuja natureza, na maioria das vezes, é não sexual, e que, ainda por cima, nada tem de inconsciente" (ZIZEK, 1991, p.132).

Freud, com efeito, foi bastante claro a esse respeito. Como ele observa, “o material disponível à elaboração onírica consiste de pensamentos — alguns deles podem ser censurados ou inacessíveis, porém, são corretamente construídos e expressos" (1916-17 [1915-17], p.206). Zizek, por sua vez, e decerto com o objetivo de indicar a diferença entre esses pensamentos e o material propriamente inconsciente, sublinha que deste material o sujeito pode "ter consciência de maneira até excessiva, pois ele o atormenta todos os dias" (1991, p.132). O fundamental é que, quer sejam censurados pela consciência, inacessíveis a ela ou presentes nela até demais, esses pensamentos são articuláveis na sintaxe da língua cotidiana, o que significa dizer que, mesmo que possam ser qualitativamente inconsciente, do ponto de vista topológico pertencem ao sistema pré-consciente/consciente.

O que a elaboração onírica faz é apenas dar “a esses pensamentos uma outra forma” (1916-17 [1915-17], p.206), ou ainda, traduzi-los, “transmitindo essa mensagem, digamos assim, através de um outro texto da linguagem” (ibidem). Sabemos que essa outra forma é aquela do sistema inconsciente, caracterizado pelo processo primário da livre circulação de energia responsável pela constituição das condensações e dos deslocamentos ou, em outros termos, regido por suas leis sintáticas próprias, responsáveis pela produção das metáforas e metonímias. Como observa Zizek “a relação entre o ‘pensamento latente’ e o que chamamos de 'conteúdo manifesto' do sonho (...) é, portanto, a relação entre um pensamento inteiramente 'normal', consciente/pré-consciente, e a tradução desse pensamento no rébus do inconsciente, do "processo primário”' (1991, p.132). 
Por que, cabe agora perguntar, dá-se essa tradução? Recorrendo mais uma vez a Zizek, podemos responder que é devido a um “curto-circuito” que ocorre entre esses pensamentos pré-consciente/conscientes e um desejo inconsciente, desejo esse que, observa Freud, é "a verdadeira força propulsora da construção do sonho” (1916-17 [1915-17], p.267), “o acréscimo indispensável (...) para cuja realização o conteúdo do sonho recebe sua nova forma” (ibidem). Assim, conclui Freud, “alguma coisa que deriva de nossa vida consciente e compartilha de suas características — nós a denominamos 'resíduos diurnos' — combina-se com alguma outra coisa proveniente dos domínios do inconsciente, a fim de se construir um sonho” (idem, p.254). Descrevendo em termos mais precisos o processo em questão: uma sequência 'normal' de pensamentos pré-consciente/ conscientes é recalcada, arrastada para o inconsciente e submetida à sua sintaxe por entrar em "curto-circuito" com um desejo já recalcado e desde sempre inconsciente, desejo necessariamente sexual e infantil, desejo com o qual os pensamentos irão se combinar para formar o sonho.

Portanto, se, a partir dessa combinação que coloca em ação a elaboração do sonho, os pensamentos oníricos são traduzidos na sintaxe do Inconsciente, o desejo inconsciente, por sua vez, não passa por tradução alguma: sua sintaxe é desde sempre a sintaxe inconsciente; não há, no que lhe concerne, inscrição alguma na sintaxe da língua cotidiana, na forma dita "normal" e "corretamente construída” de expressão. O que ocorre, na elaboração do sonho, é a imposição da forma inconsciente ao conteúdo pré-consciente/consciente do sonho.

Por isso, como observa Zizek (1991),

“não devemos reduzir (...) o trabalho interpretativo à retradução do 'pensamento latente do sonho' na linguagem 'normal', 'cotidiana', porque a estrutura é sempre ternária, há sempre três momentos: o texto manifesto do sonho, o conteúdo ou o pensamento latente do sonho e o desejo inconsciente que se articula no sonho.” (p.133)

Com efeito, se, partindo do conteúdo do sonho, podemos chegar, pela associação livre, aos pensamentos lógicos e racionalmente formalizados pré-conscientes, do desejo inconsciente, por sua vez, só temos notícias no sonho através de sua forma. Como conclui Zizek, esse desejo, que "se enxerta no sonho no espaço entre o pensamento latente e o texto manifesto, não é 'ainda mais escondido, ainda mais profundo', mas está em relação ao pensamento latente, decididamente mais na superfície (...) e seu único lugar é a forma do sonho” (ibidem).

Voltemos agora ao sonho tido pelo jovem e à interpretação que lhe dá Freud. Como observamos, ambos nos servem para ilustrar e esclarecer várias ideias e teorias freudianas. Vimos até aqui em que medida eles nos ajudam a compreender que a interpretação freudiana não deve ser confundida com a revelação 
do conteúdo oculto por trás da forma manifesta, e sim com essa própria forma. Mas, como vimos, o sonho em questão não apenas revela em sua forma manifesta o seu próprio sentido, como, mais precisamente, ele revela, sob a forma da lacuna, da falta, esse sentido. Cabe agora abordamos esse aspecto do sonho e para isso recorreremos à analogia a que lança mão Freud para explicar a produção do sonho: a associação do capitalista e do empresário.

Segundo Freud, da mesma forma que o capitalista e o empresário estabelecem entre si uma sociedade para constituírem um empreendimento, o desejo inconsciente (ou os desejos inconscientes) se associam aos pensamentos pré-conscientes para formar um sonho. Da mesma forma que um capitalista (ou um grupo de capitalistas) fornece às ideias dos empresários o capital necessário para a produção do empreendimento, os desejos inconscientes transferem aos pensamentos (ou representações) pré-conscientes a sua força, sem a qual esses pensamentos não conseguem produzir um sonho. Assim, por um lado, os pensamentos préconscientes tomam emprestado algo de essencial dos desejos inconscientes, a sua força, o que lhes permite obter a atenção da consciência e sem maiores dificuldades, nela ingressar; e por outro lado, eles emprestam a esses desejos algo para eles essencial, o ponto de ligação necessário a uma transferência, isto é, o próprio conteúdo de seus pensamentos, sem os quais o desejo não tem como se fazer representar na consciência nem tampouco se fazer realizar no sonho.

Concluindo, no sonho é despertada na consciência uma formação que apresenta conteúdos (ou representações) pré-conscientes sob a forma inconsciente, mas também dotados da força que extraíram do desejo inconsciente. Se, por um lado, o sonho nos revela o inconsciente através de sua forma, no que concerne ao desejo de onde extrai a sua força, ele só tem notícias através da forma lacunar, da falta de lembrança, da falha no discurso consciente. Ou ainda, do desejo inconsciente, da força do desejo que se realiza no sonho só podemos ter notícias por meio do que Freud chama de "umbigo do sonho", ponto no qual este mergulha no desconhecido, indicando os limites de sua representação e de sua interpretação. O fato é que não chegamos, pela interpretação do sonho, a conteúdos inconscientes. A interpretação do sonho revela a forma própria ao Inconsciente, revela o Inconsciente como uma estrutura formal. Além disso, nada mais, ou melhor, nada mais de substancial, no sentido de nada mais de substância, a não ser o mergulho no desconhecido, naquilo que Freud vai definir como o ponto central do sonho.

\section{O SONHO E A FALTA: CASTRAÇÃO E FETICHISMO}

O sonho do jovem esclarece ainda um terceiro aspecto da teoria freudiana, pois, como vimos, a falta que ele coloca em cena é uma falta bastante precisa: a falta 
do falo no corpo feminino. Como sabemos, a percepção dessa falta provoca horror nos meninos por: 1) contrariar sua teoria segundo a qual tanto os homens quanto as mulheres são dotados do falo; 2) fazê-los realizar fantasmaticamente a virtualidade da eficácia das ameaças de castração que lhes são feitas para impedir suas satisfações autoeróticas, e 3) levá-los a vivenciar o pânico diante da possibilidade da perda de seu próprio falo. Em outros termos, ela provoca horror na medida em que os ameaça narcisicamente.

Para escapar do horror dessa ameaça, o fetichista preenche a falta do falo com um substituto: o fetiche. Como observa Freud, "o fetiche é um substituto do pênis da mulher (...) em que o menino outrora acreditou e que (...) não deseja abandonar" (1927, p.180). E, por ser do falo da mulher um substituto, ele herdará o extraordinário interesse que seu narcisismo outrora dirigia ao seu próprio falo. Assim, sustenta Freud, o horror da castração ergue um monumento a si próprio na criação desse substituto (cf. FREUD, 1927, p.181).

Sobre esse substituto, Freud nos diz que ele se refere à "última impressão antes da estranha e traumática" visão do órgão genital feminino, impressão à qual o fetichista permanece fixado: pés, sapatos (partes do corpo ou do vestuário que são vistas antes que o olhar se volte para cima e se depare com a falta); peles (substitutos dos pelos pubianos, que encobrem a falta) e, sobretudo, peças de roupa íntima, que "cristalizam o momento de se despir, o último momento em que a mulher ainda podia ser encarada como fálica" (1927, p.182). Sobre o mecanismo dessa substituição, por sua vez, Freud observa que ele coloca em cena uma "solução bastante engenhosa" (1938, p.309), uma "maneira de lidar com a realidade que quase merece ser descrita como astuta" (1938, p.311).

O que esse mecanismo tem de astuto ou de engenhoso? O fato de, diante da experiência traumática da visão do órgão feminino; diante do conflito ao qual o menino se vê submetido a partir dessa visão — conflito entre reconhecer o real perigo de castração e renunciar à satisfação autoerótica ou rejeitar a realidade e convencer-se que não há razão para medo, de maneira a poder conservar a satisfação - , ser possível não se tomar nenhum dos dois partidos, ou melhor, tomar ambos ao mesmo tempo. Como observa Freud, "tanto a rejeição quanto a afirmação da castração encontram caminho na construção do próprio fetiche" (1927, p.184). Ou, em termos mais precisos: "sua ação [de substituição] contém em si própria as duas asserções mutuamente incompatíveis: 'a mulher ainda tem um pênis' e 'meu pai castrou a mulher”' (p.184). A engenhosidade da solução fetichista consiste, portanto, no fato de que, "ela responde ao conflito por duas reações contrárias, ambas válidas e eficazes” (1938, p.309).

Voltemos agora ao sonho e à interpretação que lhe dá Freud para observarmos que, tal como na fixação fetichista, a lembrança do sonhador permaneceu fixada justamente no momento em as mulheres começavam a se despir e que, 
tal como ele também, o sonhador transferiu seu interesse daquilo que encontra no próprio sonho para um suposto conteúdo que poderia estar por trás do que no sonho é encontrado. O que a interpretação freudiana do sonho indica é que não é desviando a sua atenção para aquilo que se esconde por trás da lacuna, que será revelado o segredo do sonho, visto que o seu segredo está na própria forma lacunar, faltosa, da lembrança do sonho, do órgão genital feminino.

Se agora lermos, à luz dos comentários de Freud sobre o fetichismo, a observação de Zizek a respeito do "fascínio fetichista do conteúdo por trás da forma”, somos levados à conclusão de que esse fascínio deve ser compreendido como o fascínio não por qualquer conteúdo, mas, propriamente, pelo conteúdo que, em última instância, permite ao fetichista rejeitar uma falta radical, a falta do falo na mulher, a diferença absoluta, aquilo que faz com que, para usarmos a terminologia lacaniana, 'A Mulher' não exista ou, em outros termos, a 'relação sexual' seja impossível.

Não é preciso ser fetichista, no sentido estrutural do termo, para adotar essa posição fetichista que ergue um monumento ao conteúdo oculto por trás da forma manifesta, que se fixa nos conteúdos que permitem rejeitarmos o que pode ser chamado de infinitas formas, entre as quais aquelas a que nos referimos: castração feminina, inexistência d’A Mulher ou impossibilidade da relação sexual. Citaremos aqui um único exemplo, que nos parece ilustrar de modo tão claro quanto simples, essa posição. ${ }^{1}$ Trata-se de uma interrogação bastante corriqueira no meio das mulheres. Face a vários desencontros amorosos, muitas mulheres se perguntam: "por que será que estou sempre me boicotando, buscando homens impossíveis, relações fadadas ao fracasso e ao fiasco?" Em outros termos, "que conteúdo oculto esconde essa forma de desejar marcada pela impossibilidade?"

Não é difícil observarmos que a suposição que sustenta a formulação dessa questão é a de que a impossibilidade do encontro sexual ou o fiasco próprio a todo objeto sejam uma contingência. Como resposta a essa questão, cabe, então, perguntarmos: "que crença sustenta a ideia segundo a qual a realização do desejo pode se dar fora do campo do desencontro, da impossibilidade, do fracasso, do fiasco?" No desvio do interesse do desencontro que marca - e realiza - todo encontro amoroso (forma propriamente humana de realização do desejo) para o que se esconde por trás do insistente e repetitivo encontro com o desencontro (ou com a falta); na fixação da libido nesse questionamento supostamente marcado por sua lucidez, não podemos ver senão um índice do engodo próprio ao fetichismo.

\footnotetext{
${ }^{1}$ Esse exemplo nos foi dado por Valdir Sbanko.
} 
Voltando agora mais uma vez ao sonho, podemos afirmar que é justamente com esse desencontro - com esse desencontro que o fetichista busca encobrir através do fetiche - que o jovem se encontrou no sonho. E aqui cabe lembrar de mais um detalhe fundamental (último presente que o sonho nos dá): o fato de o jovem ter, no sonho, se enganado, entrando no quarto errado; o fato que o encontro supõe o engano. Talvez por todas as características que reúne, seja esse um dos melhores exemplos freudianos do sonho como realização de desejo e, mais precisamente de realização do que Lacan chama, no final de seu Seminário XI (1964/1985), de "desejo em estado puro" (p.260), definido por ele nesse mesmo momento como não sendo outra coisa senão a especificação da Lei moral kantiana , ou seja, desejo cujo objeto não se confunde com objeto patológico, empírico ou representável; desejo cujo objeto não pode ser senão a própria falta que o constitui, objeto que Lacan, recorrendo a Freud, nomeia, no Seminário VII (1959-69/1991) de "a Coisa".

\section{O "ERRO" FETICHISTA}

Vimos que a perspicácia do fetichismo implica colocar em ação um processo que permite não apenas rejeitar a castração, mas também afirmá-la. Devemos, então, agora, para não restringirmos nossa abordagem a apenas um dos aspectos da negação fetichista, o que levaria a uma compreensão equivocada da mesma, considerar a sua ambiguidade, caracterizada, segundo os termos de Safatle, "por um duplo movimento no qual a percepção indesejada, ao mesmo tempo, é aceita e negada" (2010, p.83), movimento tornado possível, como vimos, pela instituição de um fetiche que, afirmando ao mesmo tempo duas asserções mutuamente incompatíveis - 'a mulher ainda tem um pênis' e 'o meu pai castrou a mulher' —, revela-se como a própria "contradição encarnada" (idem, p.85-86).

Para entender o processo que permite ao fetichista conciliar duas afirmações aparentemente tão incompatíveis, Safatle o aborda de início à luz da 'teoria do recalcamento parcial', esboçada em 1909 por Freud para esclarecer um caso de fetichismo. O 'recalcamento parcial', mecanismo que, nesse momento, explica o fetichismo, é definido por Freud como "um tipo de recalcamento instituído através da clivagem do complexo [representativo]" (FREUD, apud SAFATLE, p.53), uma parte do mesmo sendo recalcada enquanto a outra é idealizada, isto é, "elevada a fetiche". (ibidem)

Como esclarece Safatle:

"Pela idealização, Freud procura expor o processo através do qual o objeto é subtraído de toda determinação qualitativa capaz de servir de suporte de individuação e reduzido à condição de puro suporte de um traço genérico sobrevalorizado que 
ele deve necessariamente portar (uma peça de roupa que deve ser necessariamente usada, um atributo físico que deve ser necessariamente ressaltado), suporte de um atributo projetado pelo sujeito material a ser conformado a uma imagem-modelo libidinalmente investida. Nesse sentido, o fetiche é o que resta quando um objeto é esvaziado de toda determinação individualizadora. Resta o gozo por uma imagem infinitamente reprodutível, impessoal, dessensibilizada.” (idem, p.54)

É nesse sentido que podemos entender, sustenta Safatle, por que "Freud assume (...) que o fetichista 'ama o gênero, e não o objeto particular”. É nesse sentido também que podemos ver que a concepção freudiana de fetiche não é a de "uma espécie de objeto bruto imediatamente presente no campo do desejo" (idem, p.55), mas sim a de "uma pura fabricação, uma elaboração a partir de tal objeto, o que faz jus à raiz portuguesa da palavra, que associa fetiche e factício". (idem, p.55-56)

É a essa dimensão factícia do fetiche, indicada em 1909, que Safatle irá recorrer para esclarecer em que medida ele pode conciliar, como sustenta Freud em 1927 e 1938, duas afirmações em princípio incompatíveis. O fetiche, indica Safatle, "deve ser posto como sendo apenas um substituto que, devido ao seu caráter claramente fabricado, não esconde sua natureza de artifício” (idem, p.87). Citemos mais uma vez o autor de modo a esclarecer a astúcia própria à negação fetichista:

"No fundo, essa estratégia é uma surpreendente negação da negação. O sujeito nega a castração através de um deslocamento de valor e da produção de um objeto fetiche, mas, ao mesmo tempo, ele nega essa negação ao apresentar o fetiche como um simples substituto que não esconde para o sujeito a ausência daquilo que ele substitui. Devido ao seu estatuto peculiar, o fetiche não pode ser visto como uma representação, já que ele não é apenas presença da ausência de seu referente (o pênis feminino). No entanto, ele também não é uma apresentação de seu referente, já que não é presença imediata da coisa." (idem, p.88)

Sobre o estatuto deste objeto, o autor sugere que ele deve ser procurado em noções como a de "simulacro" e de "semblante", noções que nos ajudam a compreender a fórmula da Verleugnung: "eu sei bem que a mulher é castrada, mas mesmo assim posso gozar da aparência da sua não castração, ou seja, eu posso agir como se não soubesse" (idem, p.107). Diferentemente, portanto, do recalcamento neurótico ou da negação psicótica, ambos marcados por um 'não saber referente à verdade', a negação fetichista, sustenta Safatle, não é solidária de forma alguma de 'não saber' (idem. p.84). O que caracteriza a especificidade do fetichista é que nele há "um saber da verdade, mas isso não o impede de gozar como se 
ele não soubesse" (idem, p.107). Ainda para esclarecer essa forma específica de negação - e lançar a hipótese de sua generalização enquanto marca distintiva da subjetividade contemporânea — , ${ }^{2}$ Safatle a aproxima do que Sloterdijk um dia chamou de ideologia reflexiva — " "posição ideológica que porta em si mesma sua própria negação ou, de certa forma, sua própria crítica” (idem, p.131) — ou ainda de falsa consciência esclarecida - "figura de uma consciência que desvelou reflexivamente os móbiles que determinam sua ação 'alienada', mas mesmo assim é capaz de justificar racionalmente a necessidade de tal ação" (idem, p.131) — ou ainda, enfim, do que o autor descreve como o modo de funcionamento próprio ao cinismo, quando "eles sabem o que fazem, e continuam a fazê-lo" (ibidem).

Qual é, então, do ponto de vista da ética da psicanálise, definida em termos da ética do desejo, da verdade do desejo, o 'problema' do fetichismo? Descrito nos termos a que nos referimos até aqui, não somos levado a crer que a posição fetichista é a que melhor permite a sustentação do desejo, visto que aqui se apresentam simultaneamente o saber sobre a verdade da castração e a possibilidade de gozo pela denegação desse saber?

Pois bem, o 'problema' aqui é o da ausência da 'falta de saber'. O que falta no fetichismo é a dimensão do engano, dimensão sem a qual, como vimos, o desejo não se realiza, a verdade não se produz.

Como observa, com efeito, Zizek (1991):

“A ideia de que poderíamos desde o começo levar em conta o erro, levá-lo em consideração como erro e portanto guardar distância dele, é justamente o erro supremo da existência da metalinguagem, a ilusão de que, embora presos no processo da ilusão, poderíamos observar esse processo de uma distância 'objetiva'. Evitando nos identificarmos com o erro, cometemos o erro supremo e malogramos a verdade, porque o lugar da própria verdade se constitui através do erro.” (p.116)

Recebido em 10/1/2012. Aprovado em 23/3/2012.

\footnotetext{
${ }^{2}$ Por julgarmos bastante interessante, não nos furtamos de indicar aqui a hipótese sugerida pelo autor. Devido, entretanto, aos limites a que devemos nos ater nesse artigo, não desenvolveremos o tema.
} 


\section{REFERÊNCIAS}

FREUD, S. (1974) Edição standard brasileira das obras psicológicas completas de Sigmund Freud, Rio de Janeiro: Imago. (1900) "A interpretação de sonhos", v. IV e V.

(1916-1917 [1915-1917]) “Conferências introdutórias sobre psicanálise", v. 15.

(1927) “Fetichismo", v. XXI, p.173-185.

(1938) “A divisão do ego nos processos de defesa”, v. XXIII, p.305312.

LACAN, J. (1964/1991) O Seminário Livro 7, a ética da psicanálise, Rio de Janeiro: Jorge Zahar.

(1964/1985) O Seminário Livro 11, Os quatro conceitos fundamentais da psicanálise, Rio de Janeiro: Jorge Zahar.

SAFATLE, W. (2010) Fetichismo. Colonizar o Outro, Rio de Janeiro: Civilização Brasileira.

ZIZEK, S. (1991) O mais sublime dos histéricos. Hegel com Lacan, Rio de Janeiro: Jorge Zahar Editor.

Simone Perelson

simoneperelson@oi.com.br 